\title{
Conformidade dos comandos de operação de tratores agrícolas nacionais com a norma NBR ISO 4253
}

\author{
Dinorvan Rozin ${ }^{1}$, José F. Schlosser ${ }^{2}$, Valmir Werner ${ }^{3}$, Gismael F. Perin ${ }^{4}$ \& Paula M. dos Santos ${ }^{4}$
}

\begin{abstract}
RESUMO
O bjetivou-se, neste trabalho comparar a localização dos comandos de operação em tratores agrícolas em relação ao Ponto Índice do Assento (SIP) com as recomendações da norma NBR ISO 4253 - Acomodação do assento do operador. Fizeram parte desta análise tratores agrícolas novos, de fabricação brasileira de todas as marcas comerciais presentes no País. 0 pedal de embreagem foi o comando que melhor atendeu à norma NBR ISO $4253(51,4 \%)$, seguido dos pedais de freio $(48,2 \%)$ e do pedal de acelerador $(14,3 \%)$. A penas $23,1 \%$ dos postos de operação amostrados atenderam à referida norma, considerando a localização do centro do volante de direção dentro dos limites da área ótima especificada pela mesma. A melhor conformidade com a NBR ISO 4253 foi encontrada no posto de operação correspondente aos modelos TS100, TS110 e TS120 (versão com cabina) da marca N ew Holland (100\%), seguida do posto de operação que corresponde aos modelos 5605 e 5705 da marca John Deere $(87,5 \%)$, tal que ao posto de operação referente aos modelos MF275, MF283, MF290, M F292, M F297, M F299, M F5275, M F5285 e M F5290 (versão com cabina) da marca M assey Ferguson.
\end{abstract}

Palavras-chave: ergonomia, posto de operação, segurança, SIP

\section{Compliance of the command operations of national agricultural tractors with the NBR ISO 4253 standard}

\begin{abstract}
The aim of this study is to compare the location of command operations in agricultural tractors, measured through the Seat Index Point (SIP), with NBR ISO 4253 norms - accomodation of operator seat. This analysis included agricultural tractors manufactured in Brazil from all commercial brands available in the country. The clutch pedal was the command that best met the requirements of norm N BR ISO 4253 (51.4\%), followed by the brake pedals (48.2\%) and the accelerator pedal $(14.3 \%$ ). 0 nly $23.0 \%$ of the operation posts sampled met the requirements of the norm, placing the location of the steering wheel within the limits of the optimal area specified. The best compliance with NBR ISO 4253 was found in the operation posts of N ew Holland models TS100, TS110 and TS120 (cab model) (100\%), followed by the operation post of John Deere models 5605 and 5705 (87.5\%), as well as the operation post of Massey Ferguson models M F275, MF283, MF290, MF292, MF297, MF299, MF5275, MF5285 and MF5290, (cab model).
\end{abstract}

Key words: ergonomics, operation post, safety, SIP

\footnotetext{
1 John Deere, U nidade de Horizontina, CEP 98920-000, Horizontina, RS. Fone: (55) 3537-5000. E-mail: rozindinorvan@jonhdeere.com

2 Departamento de Engenharia Rural/U FSM, CEP 97105-900, Santa Maria, RS, Fone: (55) 3220-8175. E-mail: schlosser@smail.ufsm.br

3 Departamento de Engenharia Agrícola/Universidade Regional Integrada do Alto U ruguai e das Missões, Campus de Erechim, Rodovia RS 331, CEP 99700-000, Erechim, RS. Fone: (55) 3321-1943. E-mail: valmirw@uricer.edu.br

4 UFSM, CEP 97105-900, Santa M aria, RS. Fone: (55) 3220-8175. E-mail: gismaelperin@gmail.com; paula.san@pop.com.br
} 


\section{INTRODUÇÃO}

Atualmente, as demandas em conforto e segurança para operadores de tratores agrícolas se têm tornado cada vez mais crescentes. Segundo Dhingra et al. (2003) a definição científica para a palavra conforto pode ser "uma harmonia agradável entre fatores fisiológicos, psicológicos e físicos, entre um ser humano e o ambiente" ou, ainda, referir-se como "ausência de desconforto". Um local de trabalho deve ser sadio e agradável, proporcionar o máximo de proteção, sendo o resultado de fatores materiais ou subjetivos, prevenir acidentes, doenças ocupacionais, além de proporcionar melhor relacionamento entre a empresa e o empregado (Fiedler et al., 2006).

Segundo Cortez et al. (2007), o avanço da tecnologia e da legislação trabalhista é o principal fator passível de ter contribuído para a elaboração de projetos de máquinas agrícolas mais adequadas na minimização do desgaste físico e psíquico, tornando notória a atenção de profissionais de diversas áreas quanto à preocupação com o conforto e a segurança do operador de tratores agrícolas, no sentido de considerar os fatores humanos na concepção projetual de tratores agrícolas, em razão das adversidades impostas pela natureza no meio agrícola e também da periculosidade que essas máquinas apresentam em relação aos acidentes envolvidos neste contexto (Rozin, 2004).

Com o início de estudos enfocando a parte ergonômica dos sistemas de colheita mecanizados, começou-se a perceber que, para aumentar o rendimento da operação e diminuir o índice de doenças ocupacionais e acidentes, o posto de trabalho tinha que estar adaptado às características do trabalhador, proporcionando-lhe melhor visibilidade, com comandos ajustados à sua postura de trabalho e com maior conforto e segurança (Minette et al., 2007).

Os acidentes de trabalho são o resultado de atos e condições inseguras. Considerando a operação de tratores agrícolas, as condições inseguras se referem à máquina (trator + implemento) e ao ambiente no qual o trabalho está sendo realizado (condições do terreno, por exemplo).

$\mathrm{O}$ uso de tratores agrícolas ergonomicamente mal projetados está relacionado com o desgaste físico e a inúmeros problemas de saúde comuns de operadores de máquinas agrícolas. Tais consequências tornam imprescindível a necessidade em se considerar as características dos operadores e do seu trabalho, alcançando, deste modo, maior eficiência produtiva, maior grau de conforto e segurança na tarefa e obtendo melhoria das condições de trabalho (Fontana et al., 2004).

Debiasi et al. (2004) citam que, quando a operação de tratores agrícolas não se constitui em um sistema homem máquina eficiente, o operador é exposto a uma elevada carga física e mental. O posicionamento deficiente dos comandos de operação, degraus de acesso ao posto de operação, assento e volante de direção, dentre outros, podem ser causa indireta de muitos acidentes com tratores agrícolas. Para aumentar o rendimento da operação e diminuir o índice de doenças ocupacionais e acidentes, o posto de trabalho tinha que estar adaptado às características do trabalhador propor- cionando-lhe comandos ajustados à sua postura de trabalho, com maior conforto e segurança (Minette et al., 2007).

Segundo a norma ISO 15077, um comando de operação pode ser definido como um dispositivo acionado por uma pessoa para obter uma resposta da máquina ou de seu implemento. Para tal finalidade é necessário se conhecer o espaço de que as mãos e os braços necessitam para a apreensão e movimento e que passa a ser uma importante premissa para o planejamento de controles, comandos e demais ferramentas do local de trabalho. Schlosser et al. (2002) destacam a significação da possibilidade do operador em alcançar e acionar, com o mínimo esforço e de forma a manter uma postura corporal correta, todos os comandos (volante de direção, pedais dos freios e da embreagem, acelerador e chaves de comando) devem estar dispostos e montados sobre o posto de operação do trator agrícola, de maneira a permitir o controle através de um manuseio fácil e seguro pelo seu operador, na sua posição normal de trabalho.

O esforço para acionamento dos comandos é um aspecto imprescindível para avaliação ergonômica de máquinas, visando a um conforto maior, segurança e maior produtividade, durante a realização da jornada de trabalho, ao longo do tempo (Lima et al., 2005). Os avanços do conhecimento em ergonomia induziram a novos conceitos fazendo com que os fabricantes passassem a oferecer modelos de tratores agrícolas com melhor localização de comandos e instrumentos de controle.

Conhecer o espaço do qual as mãos e os braços carecem para a apreensão e movimento, é uma importante premissa para o planejamento de controles, comandos e demais ferramentas do local de trabalho, motivo pelo qual existem normas que estabelecem regiões de alcance para o posicionamento ergonômico dos comandos nos postos de operação de tratores agrícolas e demais máquinas autopropelidas, como a ISO 4253, na versão brasileira NBR ISO 4253 (ABNT, 1999).

Objetivou-se, com este, estudo, a conformidade da localização dos comandos de operação acionados por pés e mãos, em 35 modelos de tratores agrícolas nacionais, em relação ao ponto índice do assento (SIP), com as recomendações estabelecidas pela norma NBR ISO 4253.

\section{MATERIAL E MÉTODOS}

Realizou-se este trabalho através da amostragem quantitativa pela medição direta das dimensões dos postos de operação de tratores agrícolas de rodas, envolvendo todas as marcas de tratores agrícolas comercializados no Brasil; foram excluídos das avaliações os tratores considerados estreitos, ou seja, com bitola inferior a $1150 \mathrm{~mm}$, para evitar principalmente tratores de pequeno porte, cujas atividades se resumem em trabalhos como horticultura, olericultura e fruticultura. Assim, somente a versão do trator ou padrão foi considerada nessas situações, às quais a norma NBR ISO 4253 se aplica.

Analisaram-se 35 postos de operação utilizados em 101 modelos de tratores agrícolas nacionais, disponíveis no mercado. Essas máquinas foram divididas nas seguintes classes 
de potência bruta no motor: classe I $(\leq 50 \mathrm{~kW})$, classe II (> 50 e $\leq 75 \mathrm{~kW})$, classe III $(>75 \mathrm{e} \leq 100 \mathrm{~kW})$ e classe VI (>100 kW), agrupados de acordo com os postos de operação. Este agrupamento considerou postos de operação homogêneos, identificados de acordo com os seguintes parâmetros: tipo de posto de operação (acavalado ou plataformado); assento do operador; versão e disposição interna dos comandos de operação; desta forma, um posto de operação pode ser comum a um ou mais modelos de trator agrícola.

Analisaram-se as ocorrências dos comandos localizados na área ótima especificada pela NBR ISO 4253 (ABNT, 1999) que estabelece os limites de uma área ótima para o posicionamento dos comandos acionados pelos pés (pedal de embreagem, freios de serviço e pedal de acelerador) e o centro do volante de direção. Os limites da área ótima consideram a posição do assento do operador representada pelo SIP que referencia o operador sentado, equivalente à intersecção do plano vertical central que passa pela linha de centro do assento no eixo de rotação teórico entre o tronco e as coxas do operador. Referido ponto foi determinado, nesta pesquisa, mediante dispositivo construído de acordo com a norma ISO 5353 (Figura 1). As medidas dos comandos de operação descrita foram tomadas utilizando-se este equipamento, em relação ao SIP; utilizaram-se então, uma régua de referência horizontal e vertical graduada em milímetros e um nível de bolha.

Para determinação do SIP o assento do operador deve estar com as regulagens vertical e horizontal na posição média, desde que esteja presente no assento, segundo a norma ISO 5353. A localização do SIP sobre o posto de operação de um trator agrícola pode ser visualizada nas Figuras 2 e 3 , apresentadas numa vista superior e em perfil, respectivamente. Antes de se iniciar os procedimentos de medição, cada trator agrícola escolhido era posto plano horizontal, para evitar a propagação de erros sobre as medidas.

O detalhamento para a construção do dispositivo visando a determinação do SIP, conforme a norma ISO 5353, pode ser visualizado através das Figuras 4 e 5, em vista lateral e superior, respectivamente.

O centro do volante de direção e o SIP estão contidos no mesmo plano longitudinal vertical, plano este que divide o trator agrícola em dois hemisférios: no esquerdo e no direito. A norma NBR ISO 4253 estabelece limites laterais para o posicionamento dos comandos em relação ao SIP e aos quais os comandos de operação devem atender a fim de se manterem de acordo com a referida norma.

Posteriormente, uma linha de nylon era estabelecida horizontalmente entre o SIP e o centro do volante, fixada no dispositivo e na coluna de direção. Obtiveram-se as coordenadas do centro do volante projetando-se o centro do volante sobre a linha esticada na horizontal, com o auxílio de um fio de prumo, de um nível de bolha e de uma fita métrica.

Uma segunda linha, passando pelo SIP em posição perpendicular à linha que liga o SIP ao centro do volante, era então estabelecida, e fixada horizontalmente nas laterais do trator, com o auxílio de um esquadro de 900 e um nível de bolha. Estavam estabelecidos os referenciais para se iniciar a tomada das coordenadas dos comandos de operação. As
A.

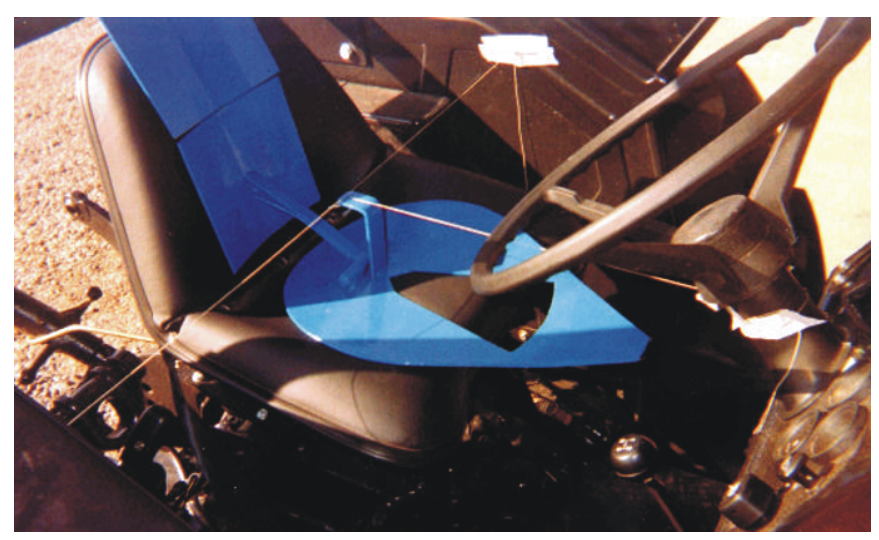

B.

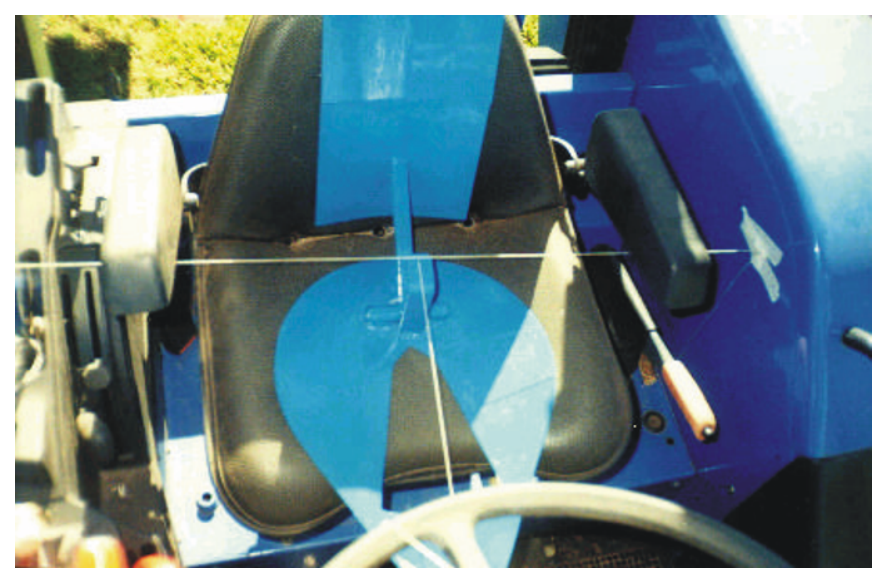

Figura 1. Dispositivo para a determinação do SIP posicionado sobre 0 assento de um posto de operação amostrado (A) e Alocação das linhas de referência sobre o dispositivo para determinação do SIP no assento do operador (B)

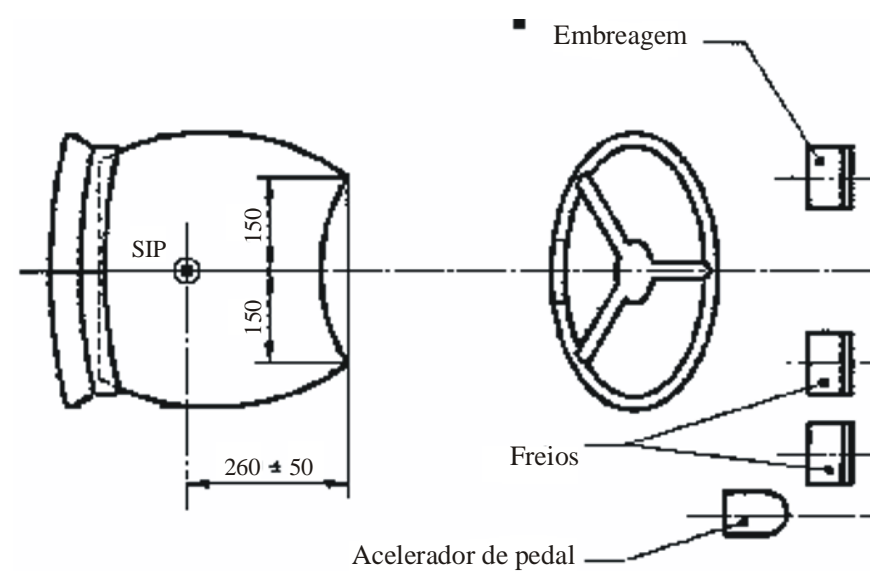

Figura 2. Localização do SIP em vista superior no posto de operação de um trator agrícola

linhas de referência dispostas sobre o dispositivo para a determinação do SIP podem ser visualizadas na da Figura 1B.

Para a análise estatística utilizou-se o teste de comparação entre duas proporções, a nível de 5\% de probabilidade de erro. Este teste estatístico foi aplicado para diferenciar as classes de potência bruta dos tratores agrícolas para cada 

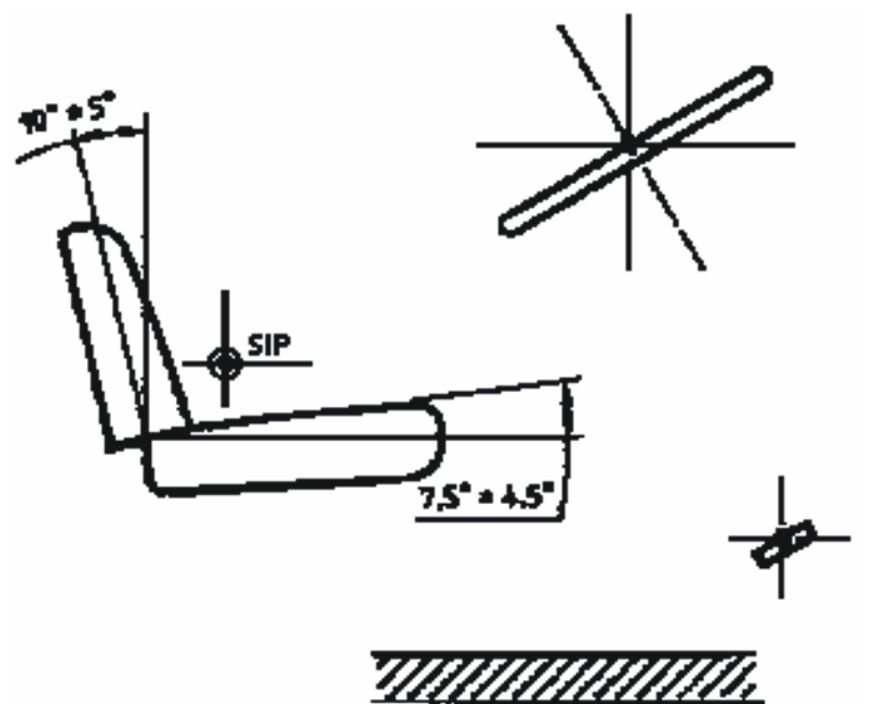

Figura 3. Localização do SIP no assento de um trator agrícola (Fonte: NBR ISO 4253)

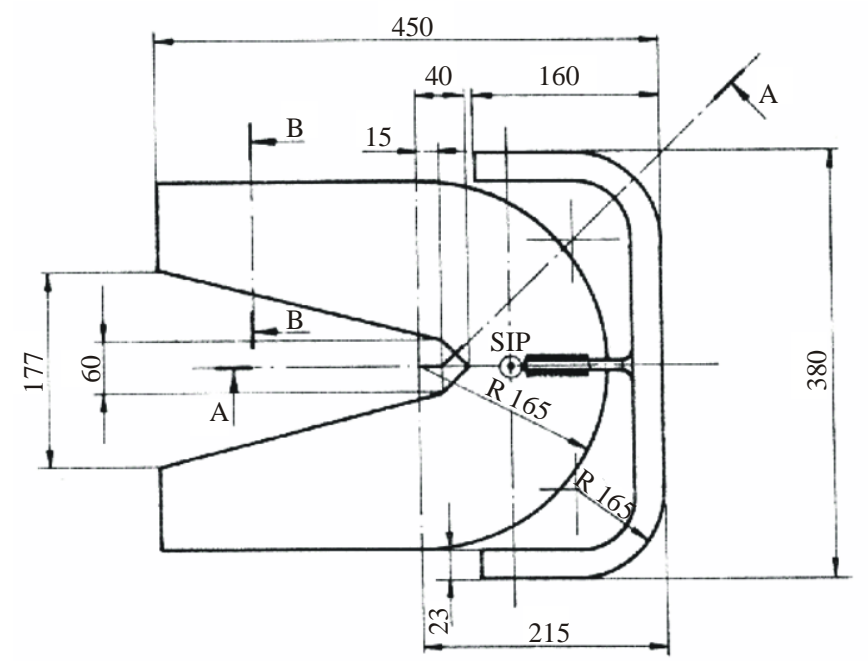

Figura 4. Detalhamento construtivo do dispositivo para determinação do SIP em vista superior (Fonte: ABNT,1999)

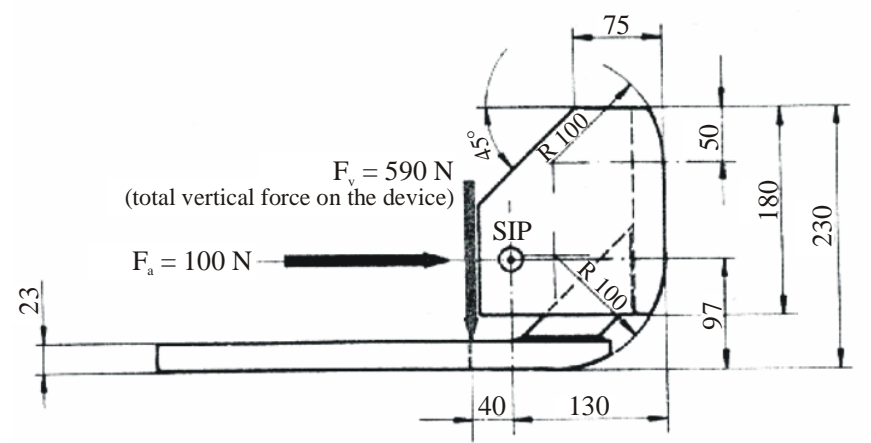

Figura 5. Detalhamento construtivo do dispositivo para determinação do SIP em vista lateral (Fonte: ABNT,1999) comando de operação individualmente, considerando-se sua localização nas áreas de alcance para o operador sentado em relação ao SIP, conforme as especificações das normas.

\section{RESULTADOS E DISCUSSÃO}

Analisando o posicionamento do comando de embreagem (pedal) localizado na área ótima especificada pela norma NBR ISO 4253, observou-se que o menor atendimento a esta norma ocorreu na Classe I $(36,4 \%)$, enquanto as demais classes a atenderam à em percentuais muito semelhantes, em torno de 55\%, com leve destaque da Classe III $(56,3 \%)$, conforme indicado na Figura 6A.

Segundo a ABNT (1999), o comando de embreagem deve estar localizado no posto de operação, de maneira a não exceder $300 \mathrm{~mm}$ nem ficar inferior $75 \mathrm{~mm}$ a partir da linha longitudinal central do trator agrícola (contida no plano longitudinal vertical), medida perpendicularmente a ela pelo lado esquerdo do operador. Analisando esta questão, concluise que todos os postos de operação amostrados apresentaram o pedal de embreagem localizado dentro desses limites estabelecidos pela mencionada norma, ou seja, obteve-se uma conformidade total. Yadav \& Tewari (1998) ao estudarem os limites do posicionamento dos pedais de embreagem chegaram à conclusão de que o afastamento lateral ótimo das pernas para os pedais de freio e embreagem variou entre 80 e $120 \mathrm{~mm}$, isto é, menores aos valores limites estabelecidos pela norma NBR ISO 4253.

Analisando os pedais de freio (esquerdo e direito) localizados na área ótima especificada pela mesma norma, verificou-se que sua maior conformidade ocorreu na Classe III, aproximadamente $72 \%$, seguida dos de Classe I (54,5\%), Classe II (50\%) e Classe IV (45,5\%). A conformidade média ficou em $56,4 \%$, considerando-se todos os tratores agrícolas abrangidos pelos postos de operação amostrados, conforme a Figura 6B. Como os pedais de freio esquerdo e direito estão alinhados perpendicularmente ao plano longitudinal vertical, os mesmos coincidem em um único ponto sobre este plano, motivo pelo qual referidos comandos foram agrupados nesta análise.

Considerando o limite lateral do pedal de freio esquerdo em relação ao plano longitudinal vertical, constatou-se que $17,1 \%$ dos postos de operação amostrados apresentaram este comando localizado a uma distância inferior à mínima de $75 \mathrm{~mm}$ estabelecida pela norma NBR ISO 4253. Em referência ao pedal de freio direito, verificou-se que $37 \%$ dos postos de operação amostrados estavam desconformes à referida norma, visto que o comando estava localizado a uma distância superior à mínima estabelecida pela norma NBR ISO 4253, ou seja, $300 \mathrm{~mm}$ a partir do plano longitudinal vertical do trator à direita do operador. A maior parte desta desconformidade se relaciona com os tratores agrícolas pertencentes às classes de potência I e II.

Analisando o acelerador de pé, verificou-se que a Classe III atendeu à norma NBR ISO 4253, com maior expressão (21,9\%), seguida da Classe I $(18,8 \%)$, da Classe II $(11,1 \%)$ e da Classe IV (9,1\%) (Figura 6C); apenas $14,9 \%$ de todos 
A.

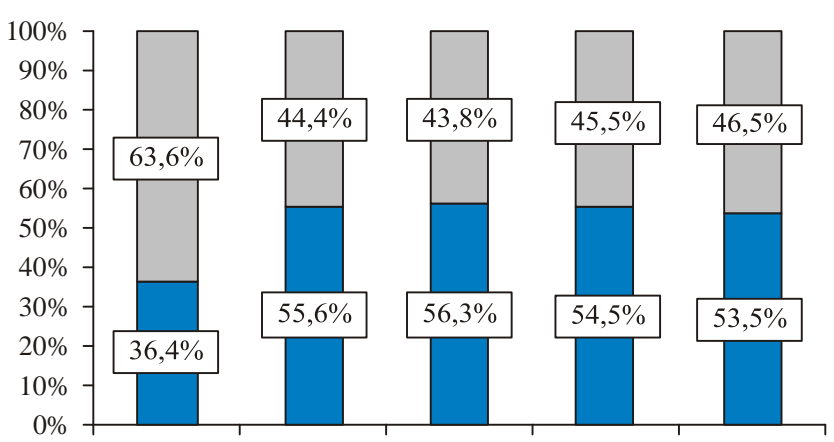

B.

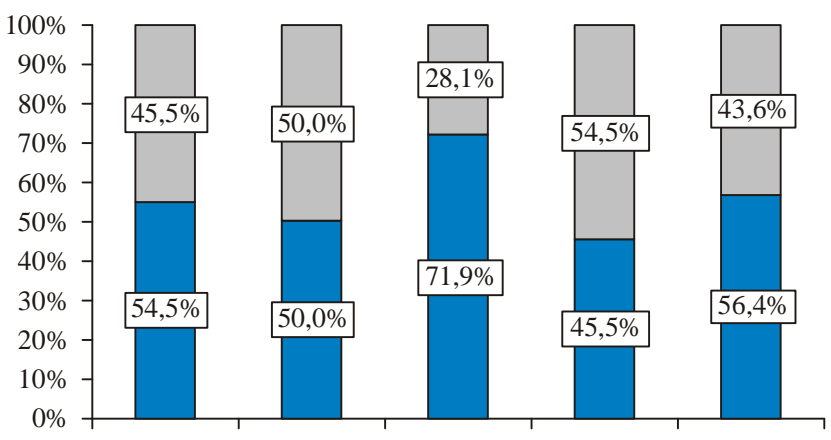

C.

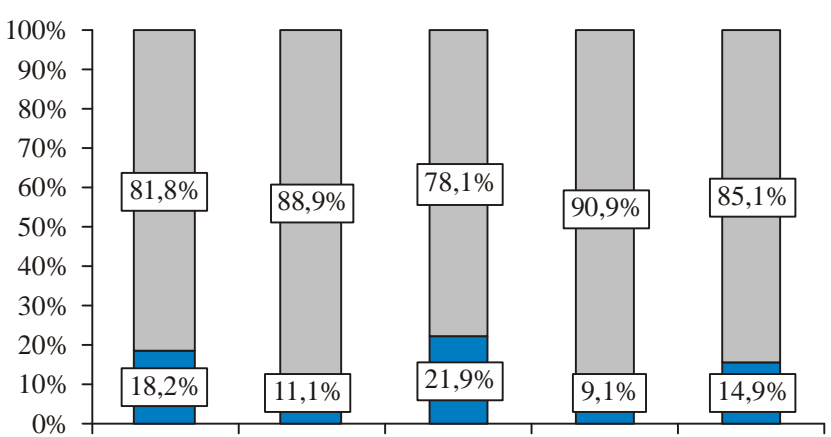

D.

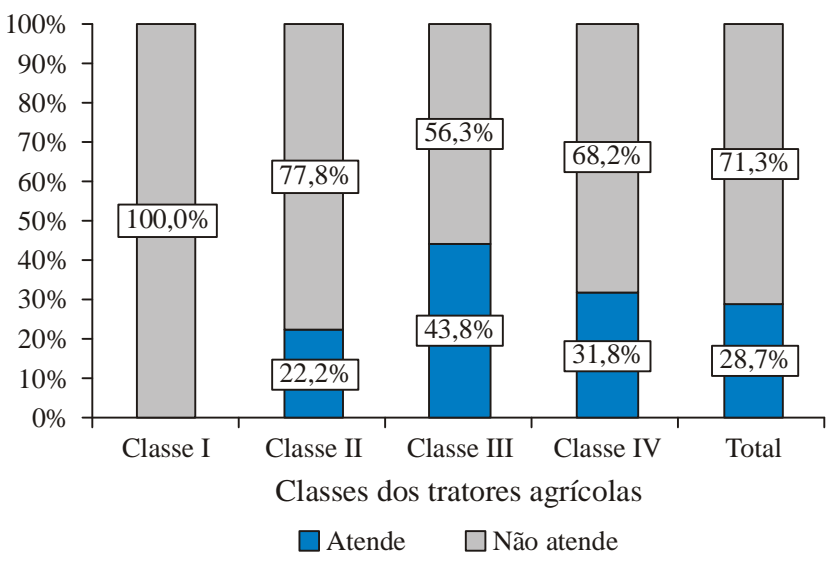

Figura 6. Conformidade: do pedal de embreagem (A); do pedal de freio de serviço (B): do acelerador de pé (C) e do centro do volante (D) em relação à norma NBR ISO 4253

os tratores agrícolas mostrados atenderam à referida norma, no que se refere à posição do pedal do acelerador, de acordo com os resultados encontrados por Fontana \& Seixas (2007) em uma avaliação de seis tratores florestais; quanto ao posicionamento de comandos nas cabines, notou-se que tanto os pedais de acelerador como os pedais de freio exigem um esforço adicional para que o operador consiga acioná-los.

O pedal de acelerador deve estar localizado no lado direito do operador a uma distância que não ultrapasse $400 \mathrm{~mm}$, perpendicularmente ao plano longitudinal vertical e medida a partir dele, segundo a mesma norma. Dos postos de operação amostrados, apenas 14,3\% não atenderam a este quesito. Tal comando esteve localizado entre os pedais de freio esquerdo e direito em $20 \%$ dos postos de operação amostrados localizado abaixo deles, o que não é recomendado; observou-se, também, que nos casos em que o pedal de acelerador não atendeu à norma, o pedal de freio direito não atendia e, nesses casos, a maioria era composta pelo posto de operação do tipo acavalado, abrangendo principalmente tratores agrícolas das classes de potência I e II.

$\mathrm{O}$ pedal de acelerador deve estar localizado à frente do plano transversal vertical do trator, de modo a não ultrapassar $90 \%$ da distância aos pedais de freio, condição esta atendida por apenas quatro postos de operação.

Analisando a ocorrência do centro do volante de direção localizado na área ótima especificada pela norma NBR ISO 4253, notou-se que a desconformidade à referida norma foi total para a Classe I, seguida da Classe II $(77,8 \%)$, da Classe IV $(68,2 \%)$ e da Classe III (43,8\%); apenas $8,7 \%$ de todos os tratores agrícolas amostrados atenderam a esta norma, de acordo com a Figura 6D. Uma comparação ergonométrica em postos de operação de colhedoras foi realizada por Kochler (1999) na região norte do Rio Grande do Sul tendo, como referência, a norma ISO 4253, verificando que a altura do centro do volante em relação ao SRP em todos os casos estudados, estava abaixo do valor mínimo estipulado pela norma.

Não houve diferença significativa entre as classes envolvidas pelo teste de comparação de duas proporções, a nível de $5 \%$ de probabilidade de erro, no que se refere à ocorrência dos pedais de embreagem, freios de serviço, pedal de acelerador e centro do volante de direção, localizados na área ótima especificada pela norma NBR ISO 4253.

Considerando-se todos os postos de operação amostrados e independentemente da sua abrangência, o pedal de embreagem foi o comando de operação que melhor atendeu à norma NBR ISO 4253, pois 51,4\% dos casos se localizaram na área ótima especificada pela mesma norma. Os pedais de freio de serviço, por sua vez, atenderam, em 48,6\%, à norma NBR ISO 4253, seguidos do centro do volante de direção $(22,9 \%)$. O pedal de acelerador foi o comando que menos atendeu à referida norma, estando localizado na área ótima de alcance para os pés, em apenas $14,3 \%$ dos postos de operação amostrados, sendo assim, obviamente, o comando que apresentou maior deficiência ergonômica dentre os comandos estudados neste trabalho.

Em relação aos postos de operação e se observando as avaliações ergonômicas, a maior conformidade com a NBR ISO 4253 foi encontrada nos modelos TS100, TS110 e TS120 (versão com cabina) da marca New Holland (100\%), seguida dos modelos 5605 e 5705 da marca John Deere (87,5\%), e ainda pelos modelos MF275, MF283, MF290, MF292, MF297, MF299, MF5275, MF5285 e MF5290 (versão com cabina) da marca Massey Ferguson. A menor conformidade 
à referida norma foi encontrada no posto de operação que corresponde aos modelos MF265, MF275 e MF283 (versão trator longo) da marca Massey Ferguson e com o posto de operação do modelo 1155.4 da marca Yanmar (25,0\%). Branquinho et al. (2002), compararam três tratores agrícolas de rodas de potência de 55,2, 77,3 e $110 \mathrm{~kW}$, com a norma ISO 4253, e concluíram que o trator modelo MF $620(77,3 \mathrm{~kW})$ foi o que apresentou o projeto ergonômico mais adaptado à referida norma, pelo fato de mostrar maior número de comandos dentro das áreas de ótimo acesso, seguido pelos modelos MF 660 (110 kW) e MF 285 (55,2 kW).

Segundo Minette et al. (2008) todas as máquinas têm alguns de seus comandos fora dos valores indicados. Uma das explicações para as desconformidades encontradas em trabalhos em ergonomia analisando conformidades de comandos ocorrer, é devido ao fato dos padrões para dimensões do posto de trabalho serem estabelecidos, de acordo com as normas suecas, para operadores com 160 a $190 \mathrm{~cm}$ de altura, em assento fixo com altura de $45 \mathrm{~cm}$ e ajustável para $5 \mathrm{~cm}$, podendo diferir das medidas dos operadores de outros países, como no Brasil (Siqueira, 1976). Assim, projetistas de máquinas devem repensar no ambiente de trabalho adequado ao operador brasileiro, sendo que nem sempre um trator agrícola, cujo posto de operação esteja dimensionado conforme os padrões definidos pelas normas internacionais pode proporcionar um ambiente de trabalho nessas condições.

\section{CONCLUSÕES}

1. O pedal de embreagem foi o comando que melhor atendeu à norma NBR ISO 4253 e o pedal de acelerador foi o que menos a atendeu.

2. No posicionamento lateral dos comandos de operação em relação ao plano longitudinal vertical, o pedal de embreagem foi o comando que melhor atendeu à norma NBR ISO 4253 e o pedal de freio direito foi o comando que menos atendeu à mesma norma.

3. A maior conformidade com a norma NBR ISO 4253 foi encontrada no posto de operação correspondente aos modelos TS100, TS110 e TS120 (versão com cabina) da marca New Holland.

4. Já o posto de operação dos modelos MF265, MF275 e MF283 (versão longo) da marca Massey Ferguson, e o do modelo 1155.4 da marca Yanmar, foram os que menos atenderam à norma em questão.

\section{LITERATURA CITADA}

ABNT - Associação Brasileira de Normas Técnicas. Tratores agrícolas - Acomodação do assento do operador - Dimensões: NBR ISO 4253. Rio de Janeiro: ABNT, 1999. 3p.
Branquinho, K. B.; Furlani, C. A.; Lopes, A.; Grotta, D. C. C. ; Silva, R. P. Avaliação ergonômica de três tratores com potência de 55,2, 77,3 e 110 kW. In: Congresso Brasileiro de Engenharia Agrícola, 31, 2002, Salvador. Anais... Salvador: SBEA, 2002. p.1-4.

Cortez, J. W.; Furlani, C. E. A.; Silva, R. P.; Ribeiro, M. P.; Oliveira, A. A. Conforto: teste ergonômicos em cabines de tratores e caminhões identificam os fatores que causam maior desgaste físico em operadores e motoristas. Cultivar Máquinas, v.63, p.22-26, 2007.

Debiasi, H.; Schlosser, J. F.; Pinheiro, E. D. Características ergonômicas dos tratores agrícolas utilizados na Depressão Central do Rio Grande do Sul. Ciência Rural, v.34, n.6, p.1807-1811. 2004.

Dhingra, H. S.; Tewari, V. K.; Singh, S. Discomfort, pressure distribution and safety in operator's seat - A critical review. Agricultural Engineering International: The CIGR Journal of Scientific Research and Development, v.5, p.1-16, 2003.

Fiedler, N. C.; Venturoli, F.; Minetti, L. J. Análise de fatores ambientais em marcenarias no Distrito Federal. Revista Brasileira de Engenharia Agrícola e Ambiental, v.10, n.3, p.679-685, 2006.

Fontana, G.; Seixas, F. Avaliação ergonômica do posto de trabalho de modelos de "forwarder" e "skidder". Revista Árvore, v.31, n.1, p.71-81, 2007.

Fontana, G.; Silva, R. P. da; Lopes, A.; Furlani, C. E. A. Avaliação de características ergonômicas no posto do operador em colhedoras combinadas. Engenharia Agrícola, v.24, n.3, p.684-694, 2004.

Kochler, M. K. A ergonomia nas colheitadeiras fabricadas no Brasil: Um estudo da evolução. Santo Ângelo: URI, 1999. 60p. Monografia Especialização

Lima, J. S. de S.; Souza, A. P. de; Machado, C. C.; Oliveira, R. B. Avaliação de alguns fatores ergonômicos nos tratores "feller-buncher" e "skidder" utilizados na colheita de madeira. Revista Árvore, v.29, n.2, p.291-298, 2005.

Minette, L. J.; Silva, E. P. da, Souza, A. P. de; Silva, K. R. Avaliação dos níveis de ruído, luz e calor em máquinas de colheita florestal. Revista Brasileira de Engenharia Agrícola e Ambiental, v.11, n.6, p.664-667, 2007.

Minette, L. J.; Souza, A. P. de; Silva, E. P. da; Medeiros, N. M. Postos de trabalho e perfil de operadores de máquinas de colheita florestal. Revista Ceres, v.55, n.1, p.66-73, 2008.

Rozin, D. Conformidade do posto de operação de tratores agrícolas nacionais com normas de ergonomia e segurança. Santa Maria: UFSM, 2004. 187p. Dissertação Mestrado

Schlosser, J. F.; Debiasi, H.; Parcianello, G.; Rambo, L. Antropometria aplicada aos operadores de tratores agrícolas. Ciência Rural, v.32, n.6, p.983-988, 2002.

Siqueira, C. A. A. Um estudo antropométrico de trabalhadores brasileiros. Rio de Janeiro: COPPE/UFRJ, 1976. 53p.

Yadav, R.; Tewari, V. K. Tractor operator workplace design - A review. Journal of Terramechanics, v.35, p.41-53, 1998. 